Short Communication

\title{
Simulation and Experimental Research on Electrochemical Machining of Cross Groove
}

\author{
Hua Lin ${ }^{1,2}$, Yuanlong Chen ${ }^{1}$, Xiang Li $^{1}$, Huigui $\mathrm{Li}^{1}$, Qi Chen ${ }^{1, *}$ \\ ${ }^{1}$ School of Mechanical Engineering, Hefei University of Technology, Hefei 230009, China \\ ${ }^{2}$ School of Mechanical and Automotive Engineering, West Anhui University, Lu'an 237000, China \\ *E-mail: qichen@hfut.edu.cn
}

doi: $10.20964 / 2021.01 .20$

Received: 14 September 2020 / Accepted: 27 October 2020 / Published: 30 November 2020

\begin{abstract}
The cross groove and its array structure are widely used in the aviation industry and the friction surface texture. Due to its unique advantages, the electrochemical machining (ECM) has broad prospects in the processing of special-shaped holes and grooves. In this work, the planar ECM of a single cross groove was taken as the object, and a cathode with an internal waist-shaped cross groove structure was designed. Further, and a three-dimensional multi-physics field coupling model was established based on the turbulent bubble flow model by coupling the model of an electric field and fluid heat transfer. The model was used to solve and analyze the bubble rate, temperature, and current density distribution in the machining equilibrium state. Thereafter, the orthogonal experiments were carried out, and the results were obtained. From the results, it was observed the groove contour quality was good, the machining process was stable, and the applied voltage and feed speed had significantly influenced the machining accuracy. Finally, the experiment produced a cross groove with an average entrance width of $2.66 \mathrm{~mm}$ and a bottom width of $2.35 \mathrm{~mm}$.
\end{abstract}

Keywords: Cross groove; Electrochemical machining; Turbulent bubble flow; Multi-physical field coupling

\section{FULL TEXT}

(C) 2021 The Authors. Published by ESG (www.electrochemsci.org). This article is an open access article distributed under the terms and conditions of the Creative Commons Attribution license (http://creativecommons.org/licenses/by/4.0/). 